HSV-1 was found in $751(70 \%)$ of all positive swabs in women $<25$ years, $141(41 \%)$ in men $<25$ years, 413 $(49 \%)$ in women $\geqslant 25$ years, and $182(23 \%)$ in men $\geqslant 25$ years.

In 1986-8, 33\% (187) of all positive swabs were due to $\mathrm{HSV}-1$, rising progressively to $56 \%$ (548) in $1998-2000(\mathrm{P}<0.0001)$. A significant rise $(\mathrm{P}<0.0001$, $1986 v 2000)$ in the proportion of isolates attributable to HSV-1 occurred in each of the four age and sex subgroups $(\mathrm{P}<0.0001)$ (figure).

\section{Comment}

Both the number and percentage of genital HSV-1 infections have risen. Genital infection with HSV-1 is strongly associated with being young (aged $<25$ years) and being female.

Explanations include changing host susceptibility and changing sexual behaviour of the population. The population seroprevalence of $\mathrm{HSV}-1$ is falling: increasing numbers of young adults are susceptible to HSV-1 infection. ${ }^{3}$ As genital tract reactivation of latent HSV-1 infection is infrequent, most new cases of genital HSV-1 infection are likely to be due to orogenital transmission, but there is no evidence suggesting that oral sex practices have changed substantially. ${ }^{4}$ The occurrence of HSV-1 infection in women, seen consistently in other studies, ${ }^{1}$ is unexplained.

These results have three important implications for management. Firstly, patients should be counselled about the more favourable clinical course of genital HSV-1 than of HSV-2 infection; recurrences are generally milder and infrequent. Secondly, subclinical shedding of HSV-1 is less common; this has a direct bearing on the likelihood of transmission. ${ }^{5}$ Thirdly, preventive strategies for genital herpes should focus on the risk of unprotected orogenital intercourse, which is frequently perceived as "safe" in the context of sexually transmitted infections.

We thank Geoffrey Clements, previously director of the West of Scotland Specialist Virology Centre.

Contributors: AS initiated and designed the study, analysed and interpreted the results, and wrote the paper. JN and NM analysed and interpreted the results and wrote the paper. GG contributed to the study design and analysis of results. WC contributed to the study design, analysis, and interpretation of the results. AS is guarantor.

Funding: No additional funding.

Competing interests: None declared.

1 Lamey P-J, Hyland PL. Changing epidemiology of herpes simplex virus type 1 infections. Herpes 1999;6:20-4.

2 Scoular A, Gillespie G, Carman WF. Polymerase chain reaction for diagnosis of genital herpes in a genitourinary medicine clinic. Sex Transm Infect 2002;78:21-5.

3 Vyse AJ, Gay NJ, Slomka M, Gopal R, Gibbs T, Morgan-Capner P, et al. The burden of infection with HSV-1 and HSV-2 in England and Wales: implications for the changing epidemiology of genital herpes. Sex Transm Infect 2000;76:183-7.

4 Johnson AM, Wadsworth J, Wellings K, Field J. Sexual attitudes and lifestyles. Oxford: Blackwell Scientific, 1994

5 Lafferty WE, Coombs RW, Benedetti J, Critchlow C, Corey L. Recurrences after oral and genital herpes simplex virus infection: influence of site of infection and viral type. N Engl J Med 1987;316:1444-9.

(Accepted 3 December 2001)

\title{
Follow up after a family based genetic screening programme for familial hypercholesterolaemia: is screening alone enough?
}

\author{
Merel C van Maarle, Marlies E A Stouthard, Perla J Marang-van de Mheen, Niek S Klazinga, \\ Gouke J Bonsel
}

Familial hypercholesterolaemia is an autosomal dominant disorder of lipoprotein metabolism, with an estimated frequency of 1 in 500 in Western countries; it results in excess mortality from coronary artery disease. ${ }^{1}$ Now that the genetic defects can be detected and statins are available to lower lipids effectively, genetic screening has been considered. ${ }^{2-3}$ In 1994 a family based genetic screening programme for familial hypercholesterolaemia started in the Netherlands. The programme's effectiveness rests on the evidence based treatment of newly identified patients. We therefore assessed the subsequent preventive care and short term clinical outcome in people testing positive for familial hypercholesterolaemia as a proxy for the expected long term level of coronary artery disease. ${ }^{4}$

\section{Participants, methods, and results}

The foundation for tracing hereditary hypercholesterolaemia performs cascade screening in families of patients with clinically diagnosed familial hypercholes- terolaemia with a known mutation, actively approaching first degree and second degree relatives. ${ }^{5}$ Family members are tested for the known mutation; their cholesterol level is not measured. The test result is communicated only to the person screened (by mail). The foundation is not involved in subsequent treatment or in monitoring follow up.

We conducted the evaluation study from March to September 1998 in all 215 people who tested positive from a consecutive cohort of 677 people screened as part of the programme. The inclusion criteria were consent to genetic testing and the current study, a positive test result, and age 18 or over.

We collected data with three self administered questionnaires-at screening and at 7 months and 18 months after communication of the test result. The main outcome measures were quality of treatment according to the key recommendations of the Dutch guidelines on hypercholesterolaemia and quality of clinical outcome by achieved cholesterol level, body mass index, and smoking status (table). ${ }^{4}$
Department of Social Medicine, Academic Medical Centre, University of Amsterdam, PO Box 22700, 1100 DE Amsterdam, Netherlands

Merel C van Maarle physician

Marlies E A

Stouthard psychologist

Niek S Klazinga professor in social medicine

Gouke J Bonsel professor in public health methods

continued over

BMJ 2002;324:1367-8 
Quality of treatment and clinical outcome in people testing positive for familial hypercholesterolaemia. Values are numbers (percentages)

\begin{tabular}{|c|c|c|c|c|}
\hline \multirow[b]{2}{*}{ Follow up } & \multicolumn{2}{|c|}{ Newly identified cases $(n=41)$} & \multicolumn{2}{|c|}{ Confirmed cases $(n=125)$} \\
\hline & $\begin{array}{c}\text { At screening } \\
\text { NR }\end{array}$ & $\begin{array}{c}\text { At follow up } \\
34 \text { (83) }\end{array}$ & $\begin{array}{c}\text { At screening } \\
\text { NR }\end{array}$ & $\begin{array}{c}\text { At follow up } \\
107(86)\end{array}$ \\
\hline Cholesterol checked & $17(41)^{\star}$ & $29(71)^{*}$ & $125(100)^{*}$ & $93(74)^{\star}$ \\
\hline Use of drugs & $0^{*}$ & $14(34)^{*}$ & $99(79)^{*}$ & $113(90)^{*}$ \\
\hline Use of statin & $0^{*}$ & $14(34)^{*}$ & $95(76)$ & $102(82)$ \\
\hline Diet & $5(12)^{*}$ & $19(46)^{*}$ & $87(70)$ & $94(75)$ \\
\hline Lifestyle advice & $0^{*}$ & $34(83)^{*}$ & $41(33)^{*}$ & $107(86)^{*}$ \\
\hline \multicolumn{5}{|l|}{ Quality of treatment: $\dagger$} \\
\hline Good & $10(24)$ & $20(49)$ & $31(25)$ & $74(59)$ \\
\hline Moderate & 0 & $4(10)$ & $58(46)$ & $27(22)$ \\
\hline Unsatisfactory & $31(76)$ & $16(39)$ & $30(24)$ & $17(14)$ \\
\hline Missing & 0 & $1(2)$ & $6(5)$ & $7(6)$ \\
\hline Known hypercholesterolaemia & $0^{*}$ & $10(24)^{*}$ & $124(99)^{\star}$ & $48(38)^{\star}$ \\
\hline Cholesterol unknown & $31(76)^{*}$ & $9(22)^{*}$ & $0^{*}$ & $8(6)^{*}$ \\
\hline Smoking & $14(34)$ & $12(29)$ & $30(24)$ & $28(22)$ \\
\hline Body mass index $>27 \mathrm{~kg} / \mathrm{m}^{2}$ & $3(7)$ & $4(10)$ & $33(26)$ & $30(30)$ \\
\hline \multicolumn{5}{|l|}{ Quality of clinical outcome: $\neq$} \\
\hline Good & $5(12)$ & $15(37)$ & $1(1)$ & $34(27)$ \\
\hline Moderate & $5(12)$ & $6(15)$ & 0 & $31(25)$ \\
\hline Unsatisfactory & $31(76)$ & $19(46)$ & 124 (99) & $56(45)$ \\
\hline Missing & 0 & $1(2)$ & 0 & $4(3)$ \\
\hline
\end{tabular}

$\mathrm{NR}=$ not relevant.

${ }^{*}$ Significant difference in time $(\mathrm{P}<0.05)$

$\dagger$ Good=use of statin (depending on cholesterol level), adherence to diet, and advice to quit smoking and lose weight if necessary; moderate=use of statin, without diet or appropriate lifestyle advice; unsatisfactory=no drugs while hypercholesterolaemic, or using cholesterol lowering drugs other than statins.

$\ddagger$ Good=cholesterol $<6.5 \mathrm{mmol} / \mathrm{l}$, body mass index $\leqslant 27 \mathrm{~kg} / \mathrm{m}^{2}$, and non-smoker; moderate=cholesterol $<6.5$ $\mathrm{mmol} / \mathrm{l}$ and body mass index $>27 \mathrm{~kg} / \mathrm{m}^{2}$, smoker, or both; unsatisfactory=cholesterol $\geqslant 6.5 \mathrm{mmol} / \mathrm{l}$ or unknown, regardless of body mass index or smoking status.

Department of Medical Decision Making, Leiden

University Medical

Centre, PO Box $9600,2300 \mathrm{RC}$ Leiden, Netherlands Perla J Marang-van de Mheen health scientist Correspondence to: M C van Maarle m.c.vanmaarle@ amc.uva.nl
We divided the people testing positive into two categories: those with an unknown cholesterol concentration or with normal cholesterol without treatment at the time of screening ("newly identified cases") and those known to have hypercholesterolaemia (cholesterol $\geqslant 6.5 \mathrm{mmol} / \mathrm{l}$ ) or being treated for this condition ("confirmed cases").

One hundred and sixty six (77\%) participants filled out all three questionnaires. Respondents and people lost to follow up differed in only one characteristic-use of statin $(57 \% v 39 \%, \mathrm{P}<0.05)$.

Seventy three (44\%) respondents were men, 41 $(25 \%)$ were newly identified, and $125(75 \%)$ were confirmed cases. The confirmed cases were older (48.2 v 38.9 years), had higher cholesterol concentrations $(10.7 v 6.0 \mathrm{mmol} / \mathrm{l})$, if known, and were more likely to have at least one first degree relative with cardiovascular disease $(62(50 \%) v 13(32 \%))$ or one premature cardiovascular death in the family (26 (21\%) v $2(5 \%))$ $(\mathrm{P}<0.05$ for all comparisons).

Although the quality of treatment and clinical outcome improved substantially over time in both groups (table), people testing positive for familial hypercholesterolaemia did not attain an optimal level of care. Quality of treatment was still unsatisfactory in $33(20 \%)$ cases, and quality of clinical outcome was still insufficient in $75(45 \%)$. Fifty eight $(35 \%)$ participants were hypercholesterolaemic at follow up, nine $(16 \%)$ of those with hypercholesterolaemia did not take statins, and $40(24 \%)$ participants smoked.

\section{Comment}

Both confirmed and newly identified patients benefit from screening for familial hypercholesterolaemia, as their risk status improves and cholesterol lowering treatment is instituted, but in almost half of all cases the achieved level of care does not keep up with current guidelines. Opportunities for improvement towards current guidelines include physician education, better implementation of guidelines, and, especially, an intensification of the link between diagnosis and follow up care in the screening process.

We thank the respondents for their enthusiasm and Marina Umans-Eckenhausen and the genetic field workers of the foundation for tracing hereditary hypercholesterolaemia for their support and help with inclusion of the study population.

Contributors: All authors conceived the study, and MCvM and MEAS collected the data. MCvM, MEAS, and GJB contributed to the analysis and interpretation of the data, and all authors contributed to the preparation of the paper. MCvM is the guarantor.

Funding: Health Research and Development Council of the Netherlands (grant number 28-2751).

Competing interests: None declared.

1 Goldstein JL, Brown MS. Familial hypercholesterolemia. In: Scriver CH, Beaudet AL, eds. The metabolic and molecular bases of inherited disease. New York: McGraw-Hill, Medical Publishing Division, 2001.

2 Randomised trial of cholesterol lowering in 4444 patients with coronary heart disease: the Scandinavian Simvastatin Survival Study (4S). Lancet 1994:344:1383-9.

3 Shepherd J, Cobbe SM, Ford I, Isles CG, Lorimer AR, MacFarlane PW, et al. Prevention of coronary heart disease with pravastatin in men with hypercholesterolemia. N Engl J Med 1995;333:1301-7.

4 Dutch Institute for Health Care, in collaboration with Dutch Heart Foundation. Treatment and prevention of coronary heart disease by lowering plasma cholesterol concentration. Utrecht: Dutch Institute for Health Care, 1998.

5 Umans-Eckenhausen MA, Defesche JC, Scheerder RL, Cline F, Kastelein JJ. Tracing of patients with familial hypercholesterolemia in the Netherlands [in Dutch]. Ned Tijdschr Geneeskd 1999;143:1157-61.

\section{One hundred years ago \\ The hygienic spittoon question in France}

At a recent meeting of the Paris Académie de Médecine M. Périer presented a report on the utilisation of spittoons in the Gare du Nord. The Académie some time ago made an appeal to the railway companies of France to place spittoons in their stations so that persons who felt inclined to expectorate might do so without danger to their fellows. The Nord Company at once placed spittoons of the pattern recommended by the Académie in its Paris terminus, and engaged trained male nurses to look after them. The spittoons have been available for about a year, but they have been very little used. Some time ago the Académie drew up a code of recommendations for the prophylaxis of tuberculosis, in which naturally the question of expectoration occupied a prominent place. A receptacle of a convenient pattern, which could be carried in the pocket and used without exciting much attention, was recommended. It was expected that the issue of this sanitary charge--for such it was intended to be- would be followed by an immediate abatement of the spitting nuisance, and that the pocket spittoon would quickly come into general use. But alas! for the vanity of the sanitarian's hopes. Some time after the publication of the document referred to, a member of the Académie of an inquiring turn of mind made a tour of the instrument makers' and pharmacists' shops of Paris and asked for the spittoon. Not one of them had it in stock, nor did it appear that there had ever been any demand for it. $\quad$ (BMJ 1902;i:223) 